\title{
2. THE CREATION OF FORMS: A TEACHING METHOD TO ENHANCE ART CREATIVITY AMONG STUDENTS IN TERTIARY INSTITUTIONS
}

\author{
Augustine Okola Bardi ${ }^{197}$
}

\begin{abstract}
The existence of creation as narrated in the biblical stories has shown that there is advancement in humanity and in many other fields of endeavour. The creativity in art has advanced the economy, social-political and technological development of not only Europe centuries ago, but also in Africa. This advancement was much earlier realized and as a result of centers of creativity which were established to better the lives in their society. With the advancement of time, art decoration which has not been giving position because of arts aesthetical contents, began to generate success not only in the West where it originated from, but also in other continents of the world. The artist including the author and art aesthetics in Nigeria has not only been encouraged this upliftment, but, has gained enough ground to be appreciated. Decoratives are created by the artists; the use of forms embellished with colours has equally been appreciated in Nigeria and the societies of the world. The usefulness of decoration has been extended for both interior and exterior decorations for beautification and for other forms to solve other human endeavours.
\end{abstract}

Key words: Creativity, Technological Development, Art decoration, Art Aesthetical, Beautification

\section{Introduction}

Centuries ago, art appreciation has been embraced in many parts of the continents of the world. Although the West first initiated this big move, other continents in their own way had the arts of culture and traditional art appreciated by its people. Traditional dance, theatrical display, as well as traditional art has its own aesthetical appreciation. The African continent has various approaches to art development rooted traditionally to commemorate events, and the creation of various forms used for historical documentation. Decorations are created by the artists. He tries as much as possible to explain his approaches to the execution of a successful art piece. Forms are of different shapes, but when researched and positioned appropriately, will create an aesthetical expression liked by art admirers. In this article, the author uses his imaginative creation of forms, these forms apart from been well constructed and interrupted, contains an aesthetical enjoyment. They can be used for interior, exterior decorations on tiles, textiles fabrics, used as tattoos, logos and on other surfaces. Again, the intention of this article is to focus on how these forms are placed in different positions such that it can help and add enough aesthetic value for use in the beautification industries. These forms are simply created and will be complimented with attractive selected colours. The author uses these techniques of form creation to teach 100 level students in the Department of Fine Applied Arts, University of Benin, Benin City. Nigeria for twenty-four years (24) who are deficient or without a credit pass in Fine art or visual arts at the West African

\footnotetext{
${ }^{197}$ Associate Professor PhD., University of Benin, from Benin City, Nigeria, email: bardiaustin@yahoo.com
} 
School Certificate (WASC) exams or the General Certificate Examination (GCE) or the National Examination Council (NECO) exams the automatic qualification to study in the Department of Fine and Applied Arts, University of Benin, Benin City. Nigeria.

\section{Materials}

\section{The following materials are used to realize this exercise.}

1. Rotring pen $0.1,0.5$ or 0.10 . 2. Acrylic colours 3. Embossed or cardboard paper (Imperial size) 4. One 2B pencil 5. Tracing paper and a ruler.

\section{Techniques in the development of forms}

Imonikebe (2010: pp. 77-81) admits that the creativity in the visual arts is mostly imaginative to develop the craftsmanship of students at lower levels in any art institution. He further writes that the creations of forms are basic fundamentals to the advancement of all students and artists alike. The following developments of forms are mainly imaginative by the author. The designs in forms are created with 2 rotring pens to achieve designs that are appealing to the eye such that admirers would as well appreciate the combination of these forms when they placed them together to enrich an aesthetical enjoyment. These forms are easy to create, but at the same time, are technically well placed to be understood. The use of freehand structuring is mostly employed in this practical exercise. Uzoagba (2010: p.28) explains that art is particularly enriching and that art cannot be learned without particular methods to achieve them. To compliment the creation of forms, Stefanescu (2017: p. 200) expresses the usefulness of drawing as a required skill for the artists to function in the visual arts. He further up-holds that, without drawing, it will be difficult for students to be creative in both the two dimensional and three dimensional designs.

\section{Approach design 1}

Here, a sample design is created as it is in figures 1 and 2. In other words, they are created to suit a particular purpose.

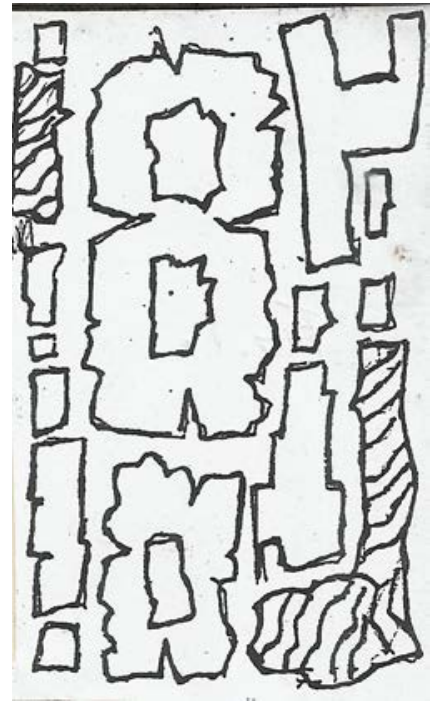

Fig. 1

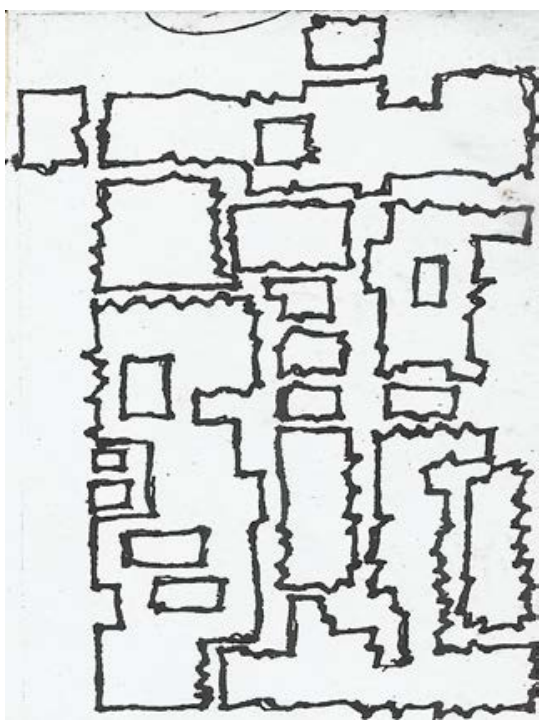

Fig. 2 
The above illustrated figures were realized with the freehand and sometimes with the use of ruler when necessary. They structures are such that at the end of the exercise, they will be easy to be coloured with the brushes recommended for the creation of forms. Okeke (1978: p. 25) describes the use of forms in visual arts as paramount and closely related to art fundamentals. He further suggests that more exercises to students are ways to innovations to art development. In the same line Mihai-Cosmin (2017 :pp. 207-208) states clearly that the artists of the $20^{\text {th }}$ century were artists specially gifted for using forms to express themselves, and that the influences of forms in their works look like works of artists like Kandinsky, Paul Klee, Lucio Fontana, Max Ernst, Pablo Picasso, Salvador Dali and many others

\section{Approach design 11}

In these part of form creation, three sets of imaginative design are to be considered as to understanding how they are put together. Okeke (1993: p. 23) writes on experimentations on form creation without limitation, and that students at the end would be sufficiently equipped with diversification in the art.

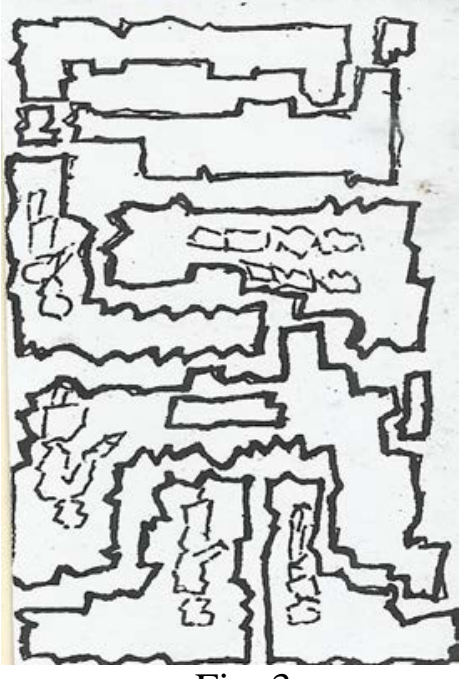

Fig. 3

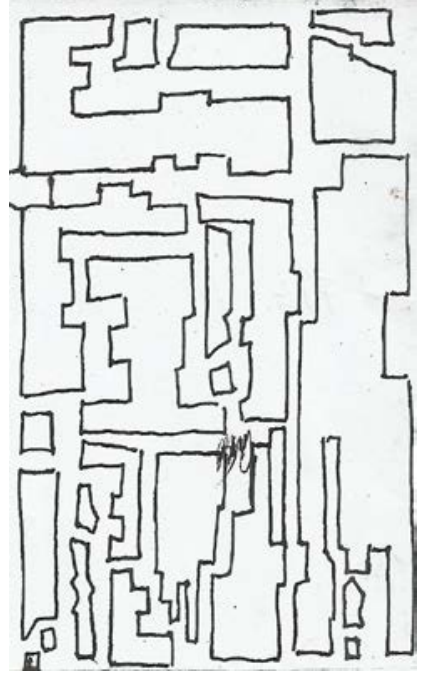

Fig. 4

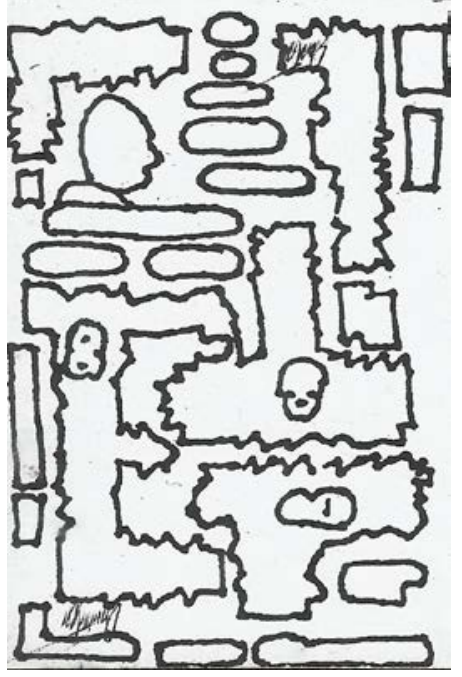

Fig.5

These figures as illustrated above are imaginative in composition. All are realized with the use of rotring pens 0.5 and 0.10 , designs were done on a $15 \mathrm{~cm}$ $\mathrm{x} 15 \mathrm{~cm}$ measured cardboard paper. The specific reason this size of cardboard paper is use is to enable the author to make a fast, accurate and a more purposeful design. The small size can easily be turned to any direction and be manipulated to accommodate a desired design. Wangboje (1985: p. 20) stresses the importance of the use of rotring pens, cardboard papers and other related materials to achieving a particular form of art. The importance of art materials he further writes helps the artists to advance in art aesthetic.

Figures 3, 4 and 5 were realized with the following instruments, there are a ruler to construct the forms the aid of rotring 0.5 and 0.10 , and the use of French curves to achieve some very difficult areas of the figures. In these designs, all unwanted lines not relevant or that may distort or disrupt the forms are quickly 
eliminate. The approved forms are darkened to make the outlines mostly at the boarders to be prominent and conspicuous in shape and sizes.

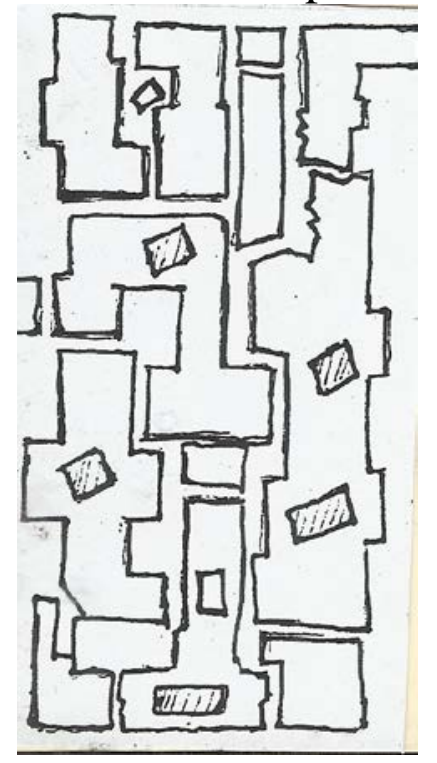

Fig. 6

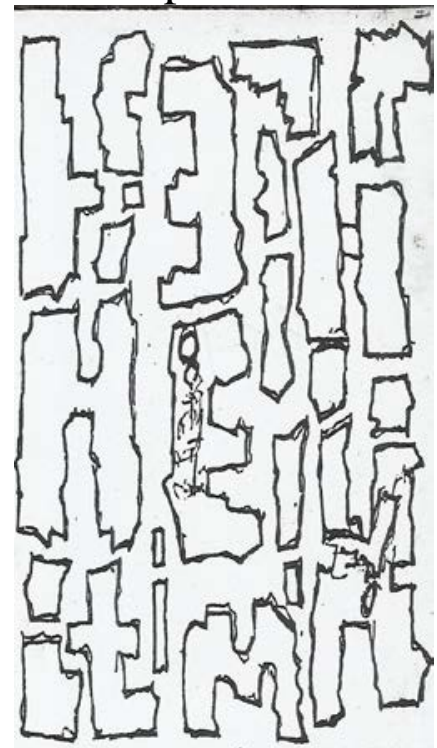

Fig.7

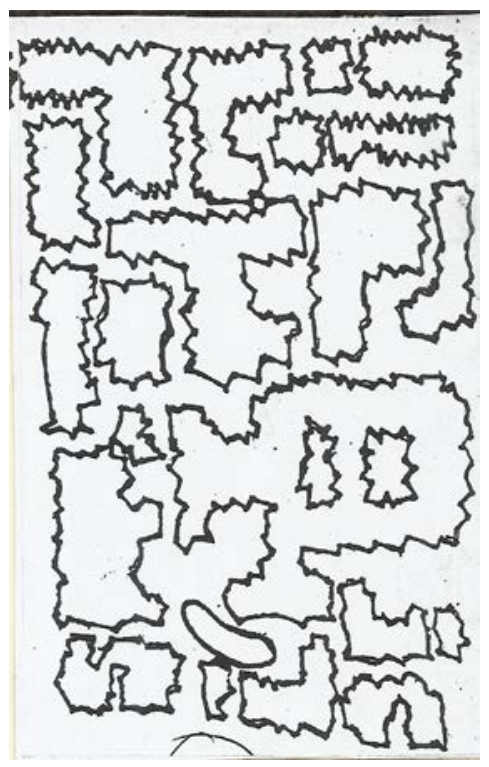

Fig. 8

Figures 6, 7 and 8 are equally created in different forms quiet different in structure compared to figures 3,4 and 5. The reason for this is to enable different designs to be closely studied by the author to make a choice. Figures 6 , 7 and 8 are particularly structured for use in the textile sector. Little wonder, the figures are a little bit complicated compared to figures 3,4 and 5. It is noticeable, that the gaps between these forms are slightly more spacious to permit and facilitate the use of colours to decorate them to specification.

In these figures also, the designs were carefully selected not only for use in interior decorations, but also on walls and on plaster of Paris (POP) settings in the parlour, dinning room and inner rooms. Willis (1987: 20-23) writes on the use of Uli forms for interior and exterior decorations and for the beautification of our environment. She traces the formation of Uli symbols a type of decoration to the putting together of various forms of art fundamentals like circles, squares, symbols and other traditional motif.

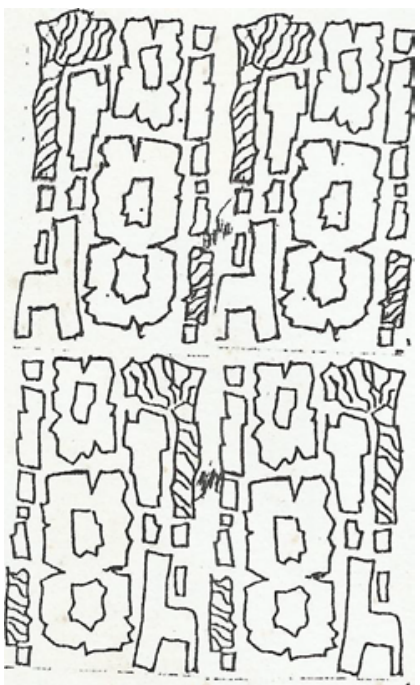

Fig. 12

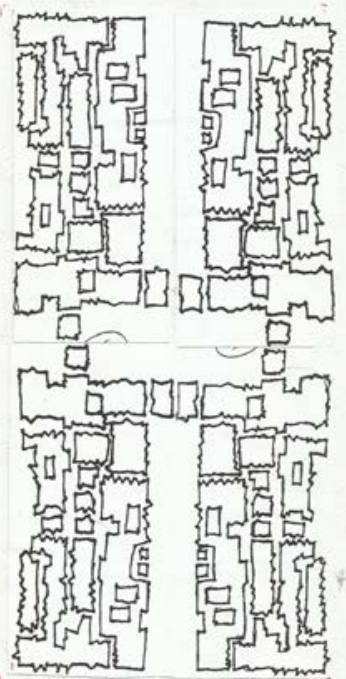

Fig. 13

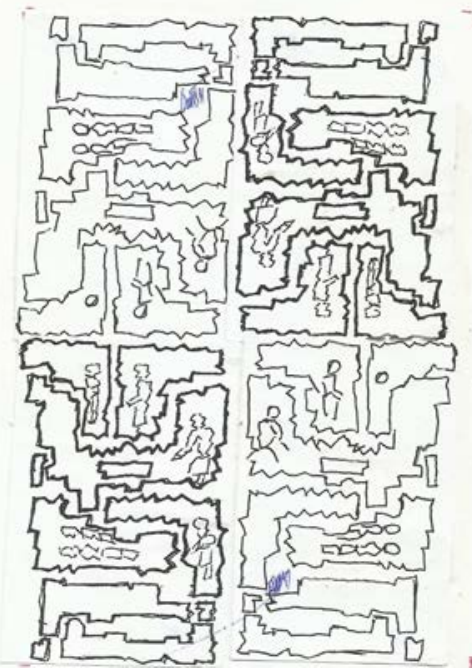

Fig. 14 
Figures 12, 13 and 14 were specially selected by the author for use as Tshirt motif. They designs are structured to suit the modern day design which is in vogue in our society. The forms are abstract in forms, and very attractive in format. They carry very unique base that will leave no one in doubt that they are purposely designed for the youths.

\section{Approach design 111}

Haven successfully achieved the constructions of forms from figures 1-11; the next approach will deal with the system of duplication to realize a much more comprehensive constructive and appreciable design form. Figures 1, 2 and 3 for instance are duplicated in three additional places as seen in Figures 12, 13 and 14. This is to enable a hitch free colouration as the exercise continues. Figures 4-8 are equally duplicated to give the following forms in Figures 15-19.

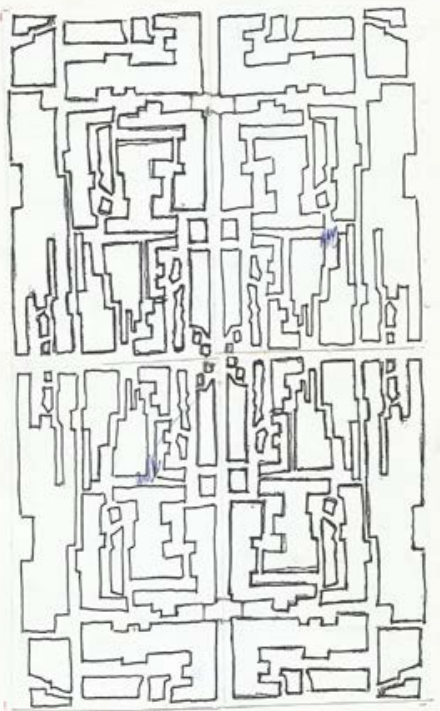

Fig. 15

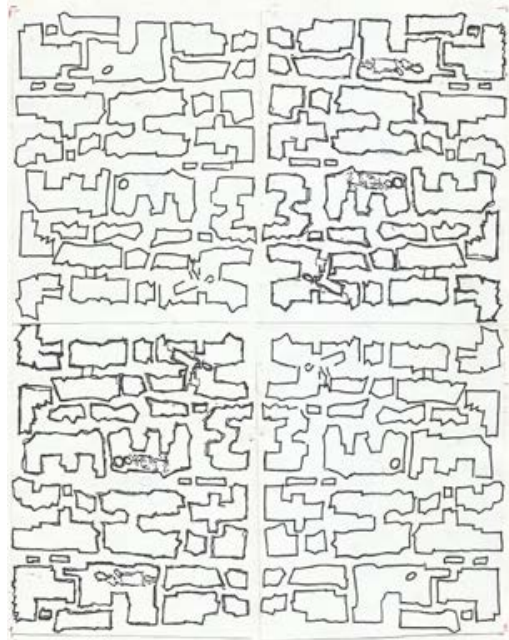

Fig. 18

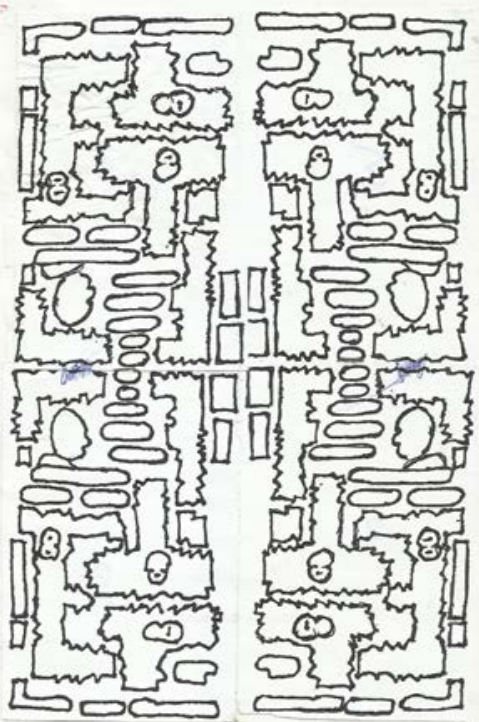

Fig. 16

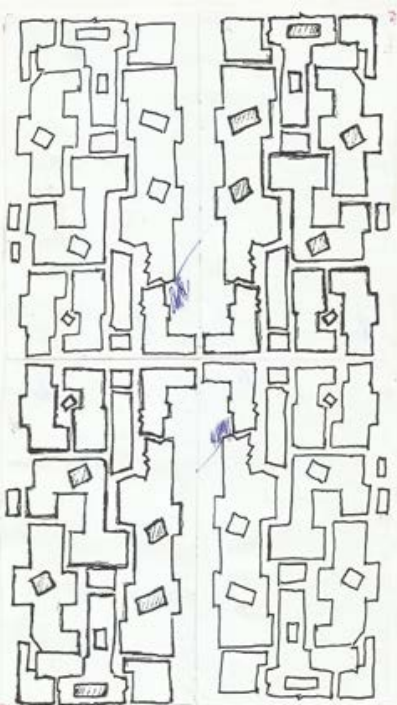

Fig. 17

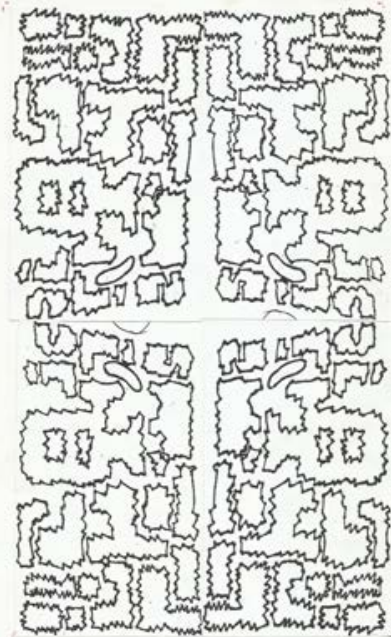

Fig. 19

Visual languages are means of communication, expression, settings and knowledge acquisition. Forms are contents of visuals which are aesthetic, constructive with emotions and a vital message is it in painting, graphics, decorative art and other arts (Arbuz-Spatari, 2017: pp. 151-152). He further describes a straight line as a movable point, the horizontal line as calm and 
static, vertical line as firm, a curved line as fullness to mention but a few (pp.152-153).

\section{Techniques in colouration}

To smoothly capture the following proceeding as techniques in colouration is sconcerned; the following must be respected to realize a hitch free exercise. Colour application must start by the edges of forms with a 0.1 brush. All outer lines must be done before the 0.5 or 0.10 brushes are used to cover the inner part of the figures. Note that during the process of colour application, a clean quarter cardboard measuring $30 \mathrm{~cm} \times 30 \mathrm{~cm}$ can be placed under the palm hand handling the brush at work to avoid colour spills from not destroying the realized work. Figures 23-30 are in full colour after the duplication seen in figures

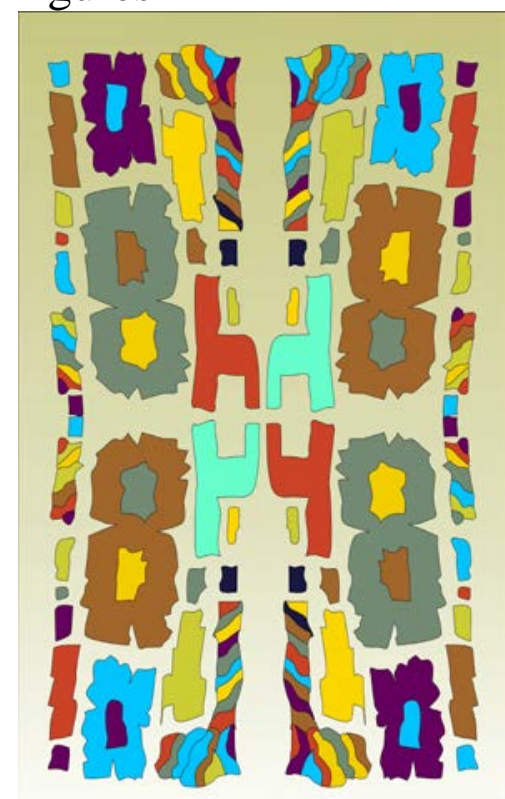

Fig. 23

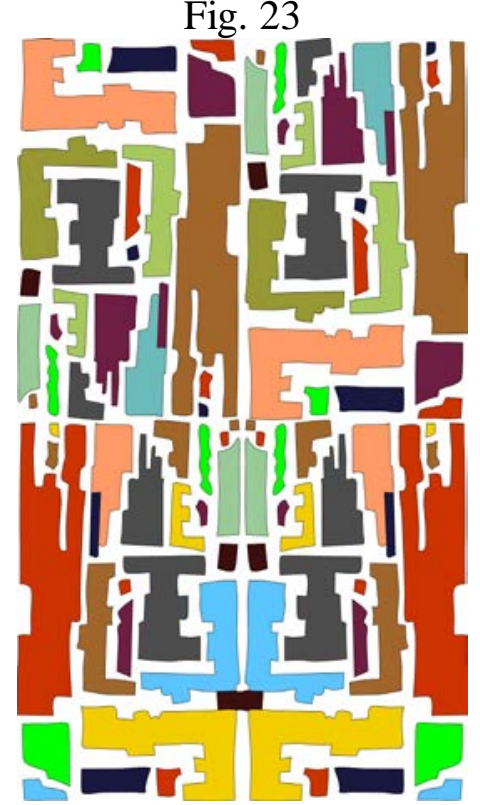

Fig. 26

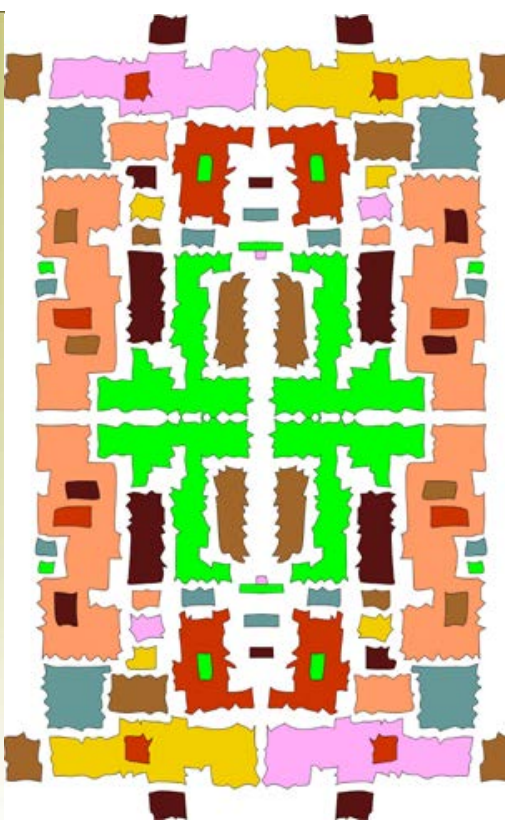

Fig. 24

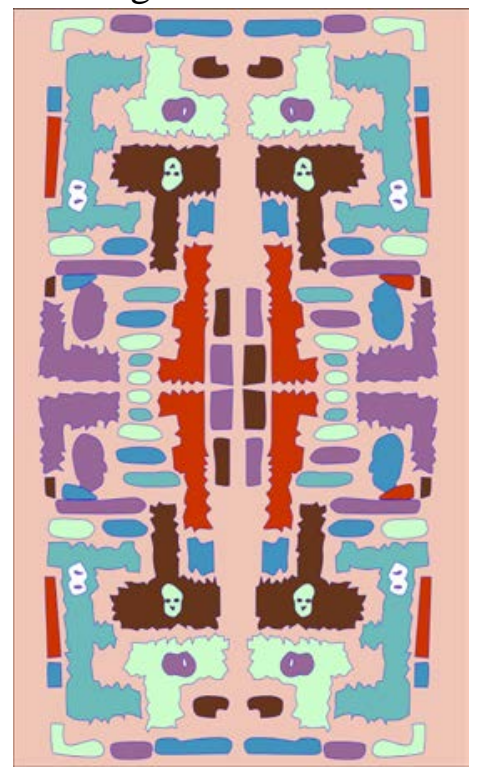

Fig. 27

12-19.

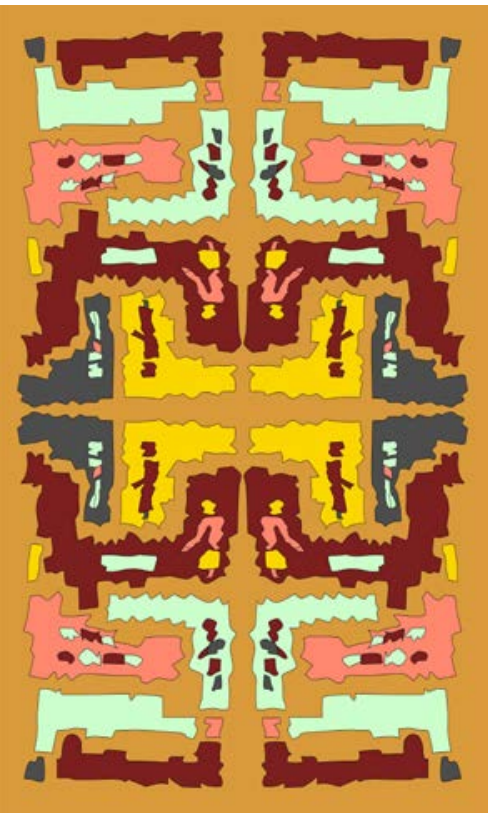

Fig. 25

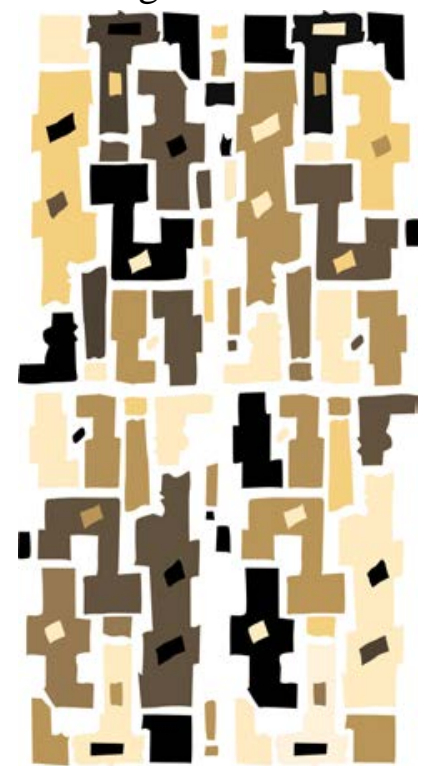

Fig. 28 


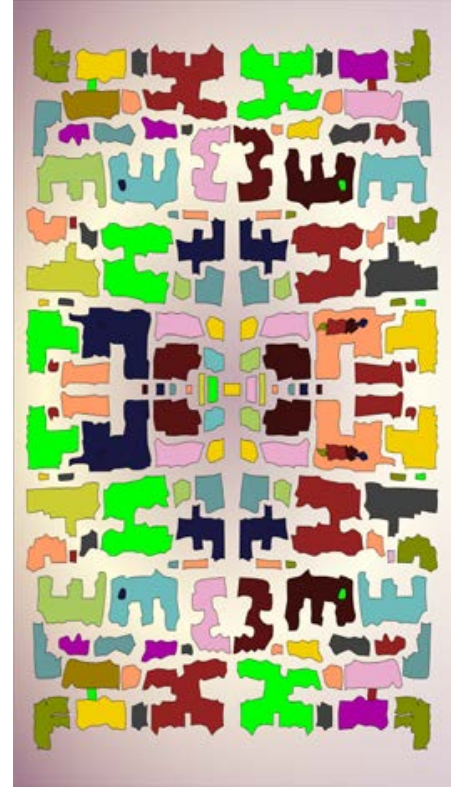

Fig. 29

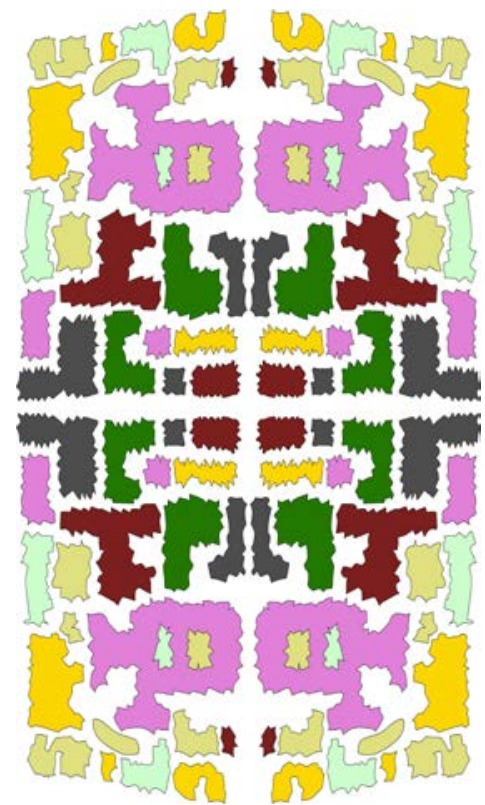

Fig. 30

\section{Results and discussions}

As stated at the opening of this article, forms are imaginative designs put together to give the aesthetical part of art. Figures 1 and 2 are introductory designs to formally launch an admirer of designs on how these forms are realized with the aid of rotring pens, brushes, acrylic colours and other materials to achieve a good design. Figures 3-8 followed the same structural composition put together by the author. Figures 12-19 are duplications of Figures 1-8. These forms are duplicated to serve many purposes, not only as interior or exterior decorations, but also useful in the textile industries and for other decorations. Duplications in negatives and positives are to have a full assemblage of design which will be more attractive when put in total colouration. Figures 23-30 shows full colours of forms that were duplicated in figures 12-19. At the final stage, figures 23-30 carry the full colouration of forms. It will be necessary as an admirer to look critically at the colour forms and make suitable choices on which forms can go as textile designs, for both interior and exterior decorations and for other uses.

\section{Conclusions}

The intention of the author is not just to create and develop forms, but to show on how forms could be fully useful for interior and exterior decorations and also in the decorative industries and in other fields of endeavour. These forms are imaginative compositions from the view of the author who is a graphic designer. The creation of these forms was used by the author also to develop students artistic knowledge in the Department of Fine and Applied Arts, University of Benin, Benin City; Nigeria who are deficient in visuals arts but were admitted to 100 level courses as syllabus B students, these pieces of design forms cannot only serve the purposes as mentioned above, but could be used for embellishment on vases and on other items in the developing decorative industries. The author wishes to develop it further for consumption by all. 


\section{Bibliography}

1. Arbuz-Spatari, O. (2017). Knowledge and Valorisation of Plastic Language and of the Folk Decorative motifs in the artistic Education Study process. Review of Artistic Education. No. 13-14, 2017. Department for Teachers Education. George Enescu University of Arts. Lasi. pp. 151-153).

2. Imonikebe, M. E. (2010), "Creativity and the teaching of visual arts in Schools". International Journal of Education. CCSD, Accra, Ghana. 1 (1). pp. 77-81.

3. Mihai-Cosmin, I. (2017). Creatvity and Innovation in visual arts through form and space having symbolic value. Review of Artistic Education. No. 13-14, 2017. Department of Teachers Education, George Enescu University of Arts. Lasi. pp. 207-208.

4. Okeke, U. (1978), "The Plastic Arts", New Culture: A Review of Contemporary African Arts. November, Vol.1. No. 1. p. 25.

5. Okeke, U. (1993), 60 ${ }^{\text {th }}$ Birthday Anniversary: A Retrospective. An Exhibition of works by Goethe Institute, Lagos. p. 23.

6. Stafanescu, M. (2017). The importance of the Drawing in the artistic creation process. Review of Artistic Education, No. 13-14, 2017. Department of Teachers Education, George Enescu University of Arts. Lasi. p. 200.

7. Uzoagba, I. N. (2010), Understanding Art in Generai Education. (Art Education Series). $3^{\text {rd }}$ Edition. Owerri: Africana February Publication Ltd. p. 28. 8. Wangboje, S. I. (1985), A Textbook on Art for Junior Secondary School. Ibadan. Nigeria: Evans Brothers. p. 20.

9. Willis, A. E. (1987). “A Lexicon of Igbo Motifs" Nsukka Journal of Humanities No. 1. June. University of Nigeria, Nsukka. pp. 20-23. 